\title{
A Comunicação, a Colaboração e o Diálogo pela Web: uma Evidência
}

\author{
José Florêncio Rodrigues Júnior ${ }^{1}$, Sonia Carvalho Leme Moura Véras² \\ ${ }^{1}$ Universidade de Brasília (UNB) aposentado \\ ${ }^{2}$ Instituto Federal de Brasília - Reitoria
}

Diretoria de Capacitação e Desenvolvimento de Pessoas, Via L2 Norte, SGAN 610 (610

Norte), Módulo D, E, F e G. Asa Norte, Brasília/DF - CEP: 70.830-450.

florenciomeister@gmail.com, veras.sonia@gmail.com

Resumo. O presente artigo tem como objetivo analisar a percepção de professores e alunos de cursos virtuais em relação à comunicação e à colaboração como fatores favorecedores da construção do diálogo entre alunos pela modalidade a distância. A metodologia de pesquisa seguiu o formato híbrido, por meio da coleta de percepções, sendo utilizados dois instrumentos: um questionário para tutores e uma entrevista semiestruturada com alunos. Como referencial teórico foram analisadas as contribuições de Vygotsky, Maçada/Tijiboy, Palloff/Pratt e Freire. Através da análise dos resultados foi percebido que a colaboração entre alunos por meio de estratégias de interação como fórum, wiki, aprendizagem baseada em problemas e estudos de caso podem contribuir para a dialogicidade que gera consequentemente a retenção e certificação de alunos nos cursos e para a construção de novos conhecimentos. Compartilhar conhecimentos e construir coletivamente foram as duas grandes vantagens evidenciadas pelos depoimentos.

Abstract. This paper aims to analyze the perception of teachers and students in courses set in virtual environments regarding the communication and collaboration as conductive factors in the construction of dialogue among students in distance education. The research methodology used consisted of a questionnaire with closed questions and semi structured interviews. The former was administered to teachers and asked about time of experience in teaching, resources used, collaboration in class, and knowledge as a social factor; the latter were conducted with students. The theoretical framework combined contributions by Vygotsky, Maçada/Tijiboy, Palloff/Pratt e Freire. The analysis of the results indicate that collaboration among students by means of strategies of interaction such as forum, wiki, problem-based learning and case method have the potential of promoting dialogue among students and, additionally, their retention and certification in their courses, as well as the construction of new knowledge. Two advantages pointed out in the statements were the sharing of knowledge and the collective construction thereof. 


\section{Introdução}

A educação não presencial tem gerado preocupação de diferentes autores desde a década de 60. Anísio Teixeira já descrevia a importância do uso da tecnologia, como recurso para transformar o modo como o docente conduzia suas aulas. Personagem central na história da educação no Brasil, nas décadas de 1920 e 1930, Teixeira (1971) acreditava que a escola deveria ser inovadora, viva, democrática, capaz de modificar a forma de pensamento do homem que compunha a sociedade. Considerava a educação como uma constante reconstrução, acreditando que era necessário "educar para formar homens livres e pensantes".

Em cem anos migramos do ambiente educativo presencial para o virtual, tornando o aluno um personagem ativo e corresponsável por sua aprendizagem. A comunicação se modificou, ampliando a troca entre professores e alunos, favorecendo o intercâmbio educacional e cultural. Acredita-se hoje numa nova dimensão qualitativa do ensino na qual se insere o ato educativo voltado para a visão cooperativa.

A transição do ambiente presencial para o virtual é evidenciada por Nicolaci-daCosta (2005), o qual afirma que é necessário entender que o mundo virtual não é um mundo paralelo ao mundo real; que ambos se completam e se "continuam". Ainda, há a emergência dos jovens transbordando objetividade e conectividade e necessitando constantemente de conexão e interação, pois estes precisam se comunicar e se sociabilizarem, mesmo que seja virtualmente.

Este tema justifica-se pelo fato de estarmos vivenciando na EAD, o período da Web 3.0 que prevê um momento de parceria, de colaboração por meio eletrônico, de aprendizagem cooperativa, onde os personagens trocam experiências e conhecimentos no decorrer dos cursos. Neste momento de intercâmbio, o conhecimento é adquirido a partir da interlocução e do interesse coletivo em aprender e ensinar. Partimos da premissa de Freire $(1987$, p.79) “... os homens se educam em comunhão, mediatizados pelo mundo".

É nessa direção que o artigo apresenta proposição de estabelecimento do diálogo como ferramenta pedagógica para uma prática docente mais humanizada, ensejando ações de valorização dos participantes do processo educativo, mantendo, assim, constante canal de comunicação que seja capaz de dinamizar a aquisição de conhecimentos.

O objetivo geral desta publicação é analisar a contribuição da colaboração no processo de estabelecimento do diálogo e na concretização da aprendizagem. Tendo como objetivos específicos: 1- Identificar as teorias pedagógicas que privilegiam a colaboração e o diálogo como pilares da aprendizagem; 2- Analisar o papel da mediação tutorial para a aproximação entre os alunos, em ambientes de ensino virtuais, de forma que se constituam como parceiros cooperativos de conhecimento e 3-Delinear os aspectos da comunicação mediada pelas tecnologias educacionais.

Nesta pesquisa foram utilizados para coleta de dados dois instrumentos: um questionário com questões objetivas para quatro tutores de um curso de graduação virtual em instituição de Ensino Superior privado do DF e uma entrevista semiestruturada para alunos da mesma instituição. Por meio destes procedimentos foi possível captar as percepções acerca da importância da colaboração para a concretização da aprendizagem e elaboração do diálogo. 


\section{Aquisição de Conhecimento via Web}

Inicialmente o uso da internet atendia a uma curiosidade do usuário por informações. Um pouco reservada, a postagem de textos visava demonstrar que a propriedade do autor estava assegurada. A apresentação dos sites na WEB era estática. Produtores e consumidores não mantinham nenhum diálogo e não havia nenhuma autoria compartilhada.

Mais para frente, a forma de produção e de recepção se modifica um pouco. Neste momento, muitos passam a trocar percepções e informações com muitos, assim, a troca passa a ser um ritual e permite a reconstrução coletiva do conhecimento, já que ao compartilhar cada um aprende um item novo, uma nova estratégia, uma nova visão, uma nova atitude. Foi atribuído um poder para a WEB, até então, não alcançado. Os participantes se conectaram pelas redes sociais e sites de relacionamento, os quais asseguraram uma aproximação entre pessoas com interesses comuns.

Chegamos à versão mais contemporânea de WEB, a 3.0, também chamada de WEB Semântica que permite aos usuários, por meio de análises e cruzamentos de dados, serem conectados a sites de interesse e que atendam às suas necessidades específicas. A personalização da WEB apresenta-se como um recurso de aproximação e comodidade via internet. Valoriza-se, a partir desta premissa, a inteligência coletiva.

\section{Comunicação - Sociabilidade - Colaboração - Diálogo}

Estudos citados por Morigi e Pavan (2004) dão conta de que, a partir das inovações e possibilidades tecnológicas, configuram-se novas formas de sociabilidade. Esta necessidade de socialização do jovem permite que ele crie suas próprias redes virtuais que, na maioria das vezes, reproduzem suas redes reais, já que o ciberespaço se constitui de uma extensão do espaço real, segundo Nicolaci-da-Costa (2005).

$\mathrm{Na}$ concepção de Simmel (2006) os indivíduos possuem várias motivações comuns para se sociabilizar, tais como paixões, desejos, instintos eróticos, impulsos religiosos, de auxílio ou instrução, de ganho ou jogo, propósitos de defesa e de ataque e diversas outras. A sociabilização começa a ter existência quando os indivíduos interagem utilizando formas de cooptação e colaboração, observando que quanto mais intensa a interação no mesmo grupo, maior sua configuração como sociedade.

Essa demanda da sociedade pela intensa interação intergrupal é sublinhada por Saraiva (1996) ao afirmar que a EAD só acontece de maneira efetiva quando há uma verdadeira "comunicação bilateral nitidamente educativa". Sendo assim, segundo Véras (2018) deve haver o comprometimento e responsabilidade de ambos os lados, tanto do professor quanto do estudante, com objetivo comum que focado no processo de aquisição de conhecimento.

Quando se tenciona desenvolver a competência de compartilhar conhecimento fazemos uso de atividades pedagógicas que mobilizem os alunos ao atingimento de metas coletivas. Ao assumir o diálogo como estratégia de investigação os alunos se posicionam mais tranquilamente para acatar o discurso dos colegas, aplicar o conhecimento e incorporar novas atitudes. Dotta (2009) destaca o momento especial em que o professor online aproveita os diálogos travados nos fóruns, propiciando uma relação mais colaborativa e interativa com os alunos, estimulando-os a serem protagonistas da própria aprendizagem. Booth e Hultén denominam esses momentos de "learning moments" (momentos de aprendizagem (In GOODYEAR et al., 2004). É crucial o papel do professor em gerar e promover esses momentos, bem assim mobilizar relações interpessoais colaborativas baseadas no respeito pelo trabalho do outro e da construção compartilhada. 
Desafio apresentado por Síveres e Balluz (2016, p. 53) no sentido da dificuldade das propostas pedagógicas fomentarem o diálogo, a partir de uma trajetória educacional hermética e enclausurada por salas e muros escolares, como é possível observar em:

Acontece que, ao longo da história da educação, na escola brasileira, encastelada em seus muros, não se proporcionou uma renovação de fato e de direito, justamente por não ter em seu interior a prática do diálogo, dificultando as possibilidades de se abrir ao mundo, e nessa abertura, desconstruir mitos e dogmas tão próprios à educação.

A esse propósito, é oportuno recorrer à contribuição de Vygotsky (1984), o qual postulava que o desenvolvimento do homem depende de um contexto sociocultural. Neste contexto ocorrem as relações interpessoais que promovem o desenvolvimento e a evolução do indivíduo. De modo consentâneo com o postulado de Vygotsky, Kenski (2007) define a educação como o processo de desenvolvimento da capacidade física, intelectual e moral da criança e do ser humano em geral visando à sua melhor integração individual e social. Principalmente pelo fato de considerarmos que é na relação interpessoal, estabelecida no interior das instituições educativas, que a criança e o jovem constroem a sua subjetividade, confrontando valores, características de personalidade e saberes.

Derivando dos posicionamentos de Vygotsky e Kenski propomos o conceito de aprendizagem cooperativa, parte integrante da EAD. Magalhães (2014) define aprendizagem cooperativa como uma sensação de interdependência positiva entre os componentes de um grupo, pois a responsabilidade de cada um vai gerar uma produção que impactará no resultado final, portando os jovens se observam integrados uns com os outros, comprometidos e aproximados (p.22).

A aprendizagem cooperativa, por sua vez, assenta-se sobre dois outros conceitos associados, isto é, cooperação e colaboração. Maçada e Tijiboy (1998) consideram que a cooperação inclui a colaboração, que se representa como interesse em auxiliar, e para existir cooperação deve haver interação, mas também objetivos comuns, atividades e ações conjuntas e coordenadas. O conceito de cooperação é mais complexo na medida em que a colaboração está incluída nele, mas o contrário não se aplica.

As atividades coletivas propiciadas por práticas pedagógicas preocupadas com esta tendência procuram utilizar plataformas de ensino que ofereçam estratégias que gerem aproximação entre os alunos. Em suma, o ambiente deve ser colaborativo para que as operações sejam feitas em sintonia com os objetivos finais das tarefas. A ajuda mútua, diálogo e a polifonia permitem que se estabeleçam os vínculos. Nas palavras de Palmieri (2003, pp. 55): "atividades cooperativas levam à expressão de comportamentos pró-sociais não somente entre as crianças, mas também entre pessoas de outras faixas etárias".

Cada vez mais, alunos que se utilizam da tecnologia como mediação para a aprendizagem têm se tornado mais autônomos, sujeitos e responsáveis pelo acesso ao próprio conhecimento. Observando este novo perfil do alunado, os professores buscam se adequar e prover auxílio somente quando solicitados pelos alunos.

Ao assumir o diálogo como estratégia de investigação os alunos se posicionam mais tranquilamente para acatar a fala dos colegas, a aplicar o conhecimento e a incorporar novos comportamentos. Importante ressaltar a relevância do diálogo na perspectiva da aproximação, do compartilhamento e da formação de vínculo. Já o 
desempenho colaborativo se retrata pela capacidade que temos de distinguir e categorizar conteúdos a partir da contribuição de todos os elementos de um grupo.

As interações sociais que ocorrem na Internet (em weblogs, fotologs, blogs, grupos de discussão, comunidades virtuais e redes sociais) buscam conectar pessoas e proporcionar a comunicação entre elas, permitindo a instauração da dialogicidade.

A construção do diálogo acontece em ambientes colaborativos em que os personagens demonstram interesse pelo discurso do outro, permitem a transparência e constroem novos conhecimentos. Observa-se que a construção frasal indutora do diálogo precisa ser baseada na clareza e correção frente à norma gramatical. Essa eficácia comunicativa foi confirmada por Palloff e Pratt (2013, p. 110), ao destacarem como competente o discurso de professores online, que utilizam a linguagem comunicacional ou dialogal.

A tecnologia, vivenciada pela internet, favorece potencialmente a relação que o homem estabelece com o conhecimento, mas somente é possível desenvolver-se uma relação interpessoal satisfatória quando essa relação é alavancada por um mediador, que faz uso de recursos diferenciados de interação, promovendo encontros virtuais, a partir de temas geradores de conhecimento dos grupos.

Observa-se essa nessa ação social nas palavras de Souza, Lima e Fonte-Boa (2015, p. 158) "Portanto, para além das tecnologias que transformaram a velocidade e a disponibilidade da informação, na visão do educador, somente pelo diálogo pode se dar um processo de conscientização e despertar para o ser "sujeito de sua própria história."

\section{Análise}

Os quatro tutores que responderam aos questionários informaram que atuam em cursos virtuais de diferentes organizações e encaminharam suas respostas por meio eletrônico.

Em relação ao tempo de atuação em tutoria, todos os tutores desenvolvem sua função como docentes virtuais num intervalos de tempo de 1 a 5 anos. Eles são unânimes em relação à questão que trata da possibilidade de se oferecer um curso sem distanciamento entre professores e alunos; ou seja, eles consideram importante que haja uma aproximação entre os personagens pedagógicos para que possa ser mediado o conhecimento.

No que tange ao uso de diferentes recursos tecnológicos favorecedores da interação entre professores e alunos nos cursos virtuais, percebemos que o fórum é utilizado por todos os tutores, o chat somente por $75 \%$ deles, a videoconferência e a wiki por 50 por cento dos tutores.

Um percentual de $75 \%$ dos tutores consideram ideal para a qualidade de um chat a participação de 6 a 10 alunos; apenas um quarto deles aceita que o chat tenha até 20 alunos em colaboração. O estudo de caso foi indicado por todos os tutores como a estratégia pedagógica mais oportuna para o desenvolvimento da colaboração entre os alunos. Metade dos mesmos respondentes considerou a produção textual como estratégia colaborativa. Somente um tutor valorizou a pesquisa como estratégia propícia à aprendizagem colaborativa.

A questão que perguntava se havia colaboração também entre os tutores indica que três dos quatro desenvolviam o hábito de trocar experiências com os demais colegas.

Em relação ao fato de estimular os alunos a participar em grupos de discussão e de comunidades virtuais, observou-se que três dos quatro tutores se dedicam a 
contribuir sensibilizando para que seus alunos se envolvam em outras formas de colaboração pela WEB. Todos os tutores concebem o conhecimento como fato social, fruto do relacionamento interpessoal, assim como todos acreditam que quando são propiciadas experiências colaborativas aos alunos o rendimento acadêmico é fortalecido. A partir da experiência em cursos virtuais colaborativos, três dos tutores perceberam que a maioria dos alunos aprecia trabalhar de forma colaborativa nas tarefas acadêmicas.

A entrevista semiestruturada realizada com 23 alunos de diferentes ambientes educacionais evidenciou que $95,6 \%$ deles acreditam que podem aprender mais na companhia de seus colegas de curso, conforme gráfico 1.

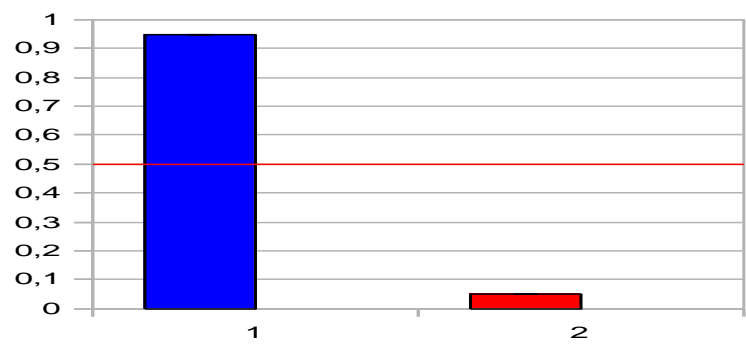

acreditam não acreditam

\section{Gráfico 1 - Colaboração e Aprendizagem (produção dos autores)}

Este mesmo número de alunos aprecia compartilhar conhecimento com os demais colegas. Embora professem credibilidade e admiração pela aprendizagem colaborativa, somente $65 \%$ dos alunos têm experiência nesta prática educativa. Isto significa que as atividades pedagógicas ainda não estão favorecendo o exercício da aprendizagem colaborativa, conforme indica o gráfico 2 .

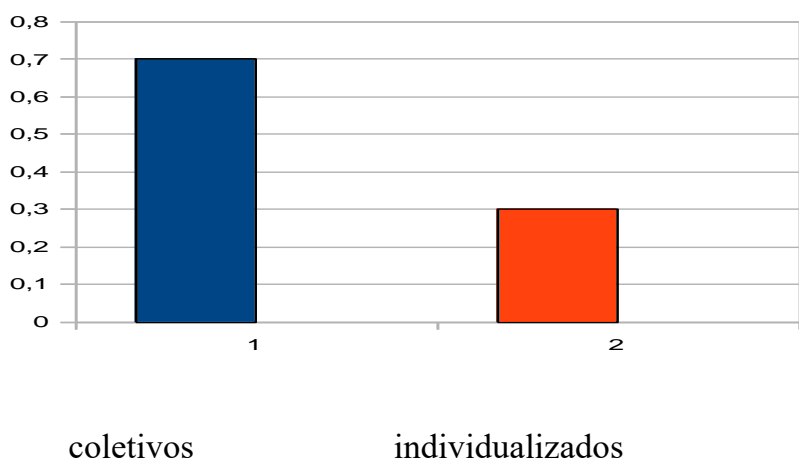

\section{Gráfico 2 - Preferência por realizar trabalhos coletivos (produção dos autores)}

Elevado percentual dos alunos (87\%) concorda que a cooperação humana parte da premissa da disponibilidade para colaborar, para buscar o consenso, para a solidariedade e o diálogo (vide gráfico 3). 


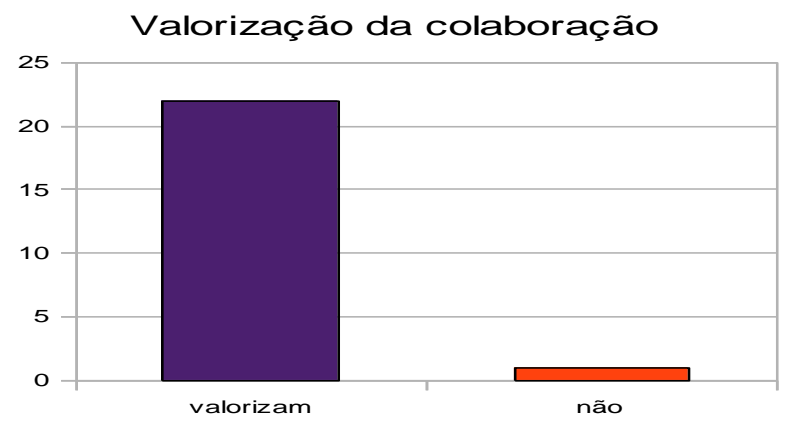

Gráfico 3 - Valorização da colaboração (produção dos autores)

De forma reduzida, seguem algumas afirmações significativas registradas durante as entrevistas para análise do tema Comunicação, Colaboração e Diálogo:

- "Valorizo a atividade colaborativa, pois o outro sabe coisas que eu não domino."

- "Caminhando com os outros conseguimos exercitar o consenso."

- "O trabalho em grupo fortalece as relações e permite uma aproximação."

- "O conhecimento precisa ser repassado de uma pessoa para outra."

- "Aprendemos com as diferenças entre as pessoas."

- "Compartilhar conhecimento e dialogar com os colegas me torna uma pessoa melhor."

\section{Considerações Finais}

Em plena era da solidariedade, é possível compreender o motivo que impulsiona as pessoas para a colaboração e para a construção coletiva. Também em situação de aprendizagem é perceptível a disposição para a colaboração e para a cooperação. Os participantes de um curso acabam por assumir objetivos compartilhados e permitem-se adquirir novos conhecimentos em parceria.

Assim, foi observado no decorrer desta investigação. Tanto professores quanto alunos se dispuseram a acolher os paradigmas dos demais parceiros. $\mathrm{Na}$ perspectiva dos personagens participantes da investigação, professores e alunos alternam papéis em busca da inteligência coletiva.

Por meio de estratégias colaborativas como o fórum, a wiki, o chat, o estudo de caso e o blog, os indivíduos externam seus conceitos e fazem observações na tentativa da troca, da argumentação e do consenso. Isso pode ser observado no decorrer das tarefas, quando os indivíduos dividem funções de pesquisa e de coleta de dados na perspectiva da construção de um só texto, a partir da premissa da parceria.

O processo educativo só se configura quando um indivíduo permite que outro atue como parceiro, como guia e como cúmplice na aquisição de conhecimento. A distância física pode ocorrer sim, distância na relação nunca. Os recursos tecnológicos muito contribuem para a aproximação e para a colaboração entre os personagens.

A inação deixou de existir no interior das salas de aula virtuais. Uma modalidade de ensino/aprendizagem que se propõe a mobilizar as pessoas a construir coletivamente o conhecimento é mais do que agregadora, é cidadã. 
Este estudo finaliza com a perspectiva que os indivíduos em colaboração formam uma rede que se fortalece no compromisso, na aceitação, na reciprocidade e na construção de conhecimentos compartilhados que não podem mais ser dissociados. $\mathrm{E}$ com a convicção de que tutores e alunos valorizam a colaboração e a cooperação por meio da tecnologia interativa. São necessárias as metodologias pedagógicas específicas para o favorecimento da aproximação, do diálogo e da diminuição da distância transacional entre os personagens.

\section{Referências}

BOOTH, S. e HULTÉN, M. Research on networked learning: An overview. In: GOODYEAR, P. , BANKS, S., HODGSON, V E.e McCONNELL, D. Advances in research on networked learning. Boston: Kluwer Academic Publishers, 2004.

DOTTA, S. Aprendizagem no Presencial e a Distância. São Paulo: Papirus 2006.

KENSKI, V. M. Educação e tecnologias: o novo ritmo da informação. 1. ed. Campinas: Papirus, 2007.

MAÇADA, D. L. e TIJIBOY, A.V. Aprendizagem Cooperativa em ambientes telemáticos. IV Congresso RIBIE, 1998.

MAGALHÃES, A. M C. Aprendizagem colaborativa enquanto estratégia para promoção da atenção dos alunos. Universidade de Lisboa, 2014.

MORIGI, V. J.; PAVAN, C. Tecnologias de Informação e Comunicação: novas sociabilidades nas bibliotecas universitárias. In: Ciência da Informação, Brasilia, v 33, n 1, p 117 a 125, jan/abr 2004.

NICOLACI-DA-COSTA, A. M. "Sociabilidade virtual: separando o joio do trigo". In: Psicologia \& Sociedade, vol 17, n 2, p 50 a 57, mai/ago 2005.

PALMIERI, M. W. A. Cooperação, competição e individualismo: Uma análise microgenética de contextos de desenvolvimento na pré-escola. Tese de Doutorado, Universidade de Brasília-DF, Brasília - Distrito Federal, 2003.

PALLOFF, R. M.; PRATT. O instrutor online: estratégias para a excelência profissional. Porto Alegre: Penso Editora, 2013.

PALMIERI, M. W., \& BRANCO, A. U. Cooperação, competição e individualismo em uma perspectiva sócio-cultural construtivista.In: Psicologia Reflexão \& Crítica, 17(2), 189-198, 2004.

SIMMEL, G. Questões Fundamentais da Sociologia: indivíduo e sociedade. Rio de Janeiro: Zahar, 2006.

Sousa, C. A. de M. LIMA, D. M. S. FONTE-BOA, F. Jovens universitários de Licenciatura e a EAD em seus cursos presenciais. In: Juventudes e Tecnologiassociabilidades e aprendizagens. Brasília: Liber Livro, 2015.

TEIXEIRA, A. Cultura e tecnologia. Rio de Janeiro: FGV/Instituto de Documentação, 1971.

SARAIVA, T. Educação a distância no Brasil: lições da história. In: Em Aberto, Brasília, DF, v. 16, n. 70, p. 17-27, 1996.

SÍVERES, L. BALLUZ, E. H. A. S. Diálogos: desafios e possibilidades para (re)pensar a prática docente. In: Diálogo - um princípio pedagógico. Capítulo 3. Brasília: Liber livro, 2016. 
VÉRAS, S. C. L. M., RODRIGUES JR., J. F. Aprendizagem em grupo no ambiente virtual. In: Revista Poisson, cap. XV, volume 6, p. 104-111. 2018.

VYGOTSKY, M. A formação social da mente. São Paulo: Martins Fontes, 1984. 